\title{
Correction of Abnormal Renal Blood Flow Response to Angiotensin II by Converting Enzyme Inhibition in Essential Hypertensives
}

Jamie Redgrave, Steven Rabinowe, Norman K. Hollenberg, and Gordon H. Williams

Endocrine-Hypertension Unit and Department of Radiology, Brigham and Women's Hospital and Harvard Medical School, 75 Francis Street, Boston, Massachusetts 02115

\section{Abstract}

In $40-50 \%$ of patients with essential hypertension, a high sodium intake does not increase renal blood flow (RBF). These patients have been defined as nonmodulators because sodium intake does not modulate renal and adrenal responsiveness to angiotensin II (AII). To define the role of AII in mediating this altered responsiveness, we assessed the effect of a converting enzyme inhibitor (enalapril) on RBF and its responsiveness to AII in 25 patients with essential hypertension-10 modulators and 15 nonmodulators-and 9 normotensive controls. After $5 \mathrm{~d}$ of a 200-meq sodium intake, the nonmodulators did not increase RBF, whereas the normotensives $(79 \pm 28 \mathrm{ml} /$ min per $\left.1.73 \mathrm{~m}^{2}\right)$ and modulators $\left(75 \pm 26 \mathrm{ml} / \mathrm{min}\right.$ per $\left.1.73 \mathrm{~m}^{2}\right)$ did $(P<0.025)$. Arterial blood pressure did not change in the modulators with the salt loading, whereas in the nonmodulators, blood pressure rose $(P<0.004)$.

After enalapril administration for $66 \mathrm{~h}$, there was a significant difference $(P<0.01$, Fisher Exact Test) in the blood pressure response in the two hypertensive subgroups. In the modulators, there was no change; in the nonmodulators, despite the high salt diet, a blood pressure reduction occurred. In parallel, basal RBF and RBF responsiveness to AII were not changed after converting enzyme inhibition in the normotensive control $(n=9)$ or the hypertensive modulators $(n=10)$. Conversely, in the nonmodulators $(n=14)$, the basal RBF increased significantly $\left(83 \pm 25 \mathrm{ml} / \mathrm{min}\right.$ per $\left.1.73 \mathrm{~m}^{2} ; P=0.01\right)$, the increment being indistinguishable from the response to salt loading in normal subjects. Furthermore, renovascular responsiveness to infused AII was also significantly enhanced $(P$ $=0.027)$ in the nonmodulators, suggesting that enalaprilinduced increase in RBF reflected a fall in intrarenal AII levels, and not an increase in prostaglandins or kinins, which would have blunted the renal response to AII.

Thus, short-term converting enzyme inhibition corrected abnormalities in sodium-mediated modulation of renal vascular responsiveness to AII. The close quantitative relation of the increase in RBF with sodium loading in normal subjects and modulators, and with converting enzyme inhibition in nonmodulators, viewed in the context of the effectiveness of enalapril only in the latter, and parallel shifts in sensitivity to AII, raises the intriguing possibility that converting enzyme inhibition reversed the failure of the renal blood supply to respond to

Address reprint requests to Dr. Williams, Endocrine-Hypertension Unit, Brigham and Women's Hospital, 75 Francis Street, Boston, MA 02115.

Received for publication 30 July 1984 and in revised form 19 December 1984.

J. Clin. Invest.

(c) The American Society for Clinical Investigation, Inc. 0021-9738/85/04/1285/06 \$1.00

Volume 75, April 1985, 1285-1290 sodium loading. Thus, converting enzyme inhibitors may reduce blood pressure specifically in this subset of patients with essential hypertension, who are sodium sensitive by way of mechanisms more closely related to local than systemic activity of the renin-angiotensin system.

\section{Introduction}

We have shown that $\sim 40 \%$ of patients with essential hypertension, $50 \%$ of normal and high renin subjects, fail to increase renal plasma flow or to enhance renal vascular responsiveness to angiotensin II (AII) ${ }^{1}$ when they shift from a low to a high sodium intake $(1,2)$. This combination of abnormalities raises the intriguing possibility of an inappropriate level or action of AII within the kidney. There is an abnormal adrenal response to AII in similar patients, and converting enzyme inhibition restores normal adrenal responsiveness (1-5). We have termed these individuals nonmodulators since sodium intake does not modulate renal vascular or adrenal responses to AII. The purpose of this study was twofold; first, to confirm that nonmodulators indeed fail to increase renal plasma flow in response to a high sodium intake, and second, if so, to ascertain whether converting enzyme inhibition modifies these patients' renal blood flow (RBF) and their renal vascular responsiveness to AII.

\section{Methods}

25 patients with normal or high-renin essential hypertension (age range, 24-65 yr) and nine normotensive subjects (age range, 22-42 yr) were studied in the Clinical Research Center of the Brigham and Women's Hospital. Some of the results in the normal subjects have been reported previously (6). Patients with low-renin essential hypertension, defined as those having a plasma renin activity in response to upright posture on a $10 \mathrm{meq} \mathrm{Na}$ diet of $<2.4 \mathrm{ng} / \mathrm{ml} \mathrm{per} \mathrm{h}$, were excluded (7). Each hypertensive had had outpatient diastolic blood pressure measurements in excess of $90 \mathrm{mmHg}$ on at least three occasions and documented evidence of hypertension for at least 6 mo before the study. Patients with secondary forms of hypertension were excluded by standard methods (2).

All antihypertensive medications were discontinued for at least 2 wk before study. All subjects were fed constant, isocaloric diets during their hospitalization. Initially, subjects were placed on a 10 meq Na and $100 \mathrm{meq} \mathrm{K}$ diet. After balance had been achieved ( $7 \mathrm{~d})$, subjects were given a $200 \mathrm{meq} \mathrm{Na}, 100$ meq $\mathrm{K}$ intake for $8 \mathrm{~d}$. Fluid intake was maintained at $2,500 \mathrm{ml} / \mathrm{d}$ (Fig. 1). Daily 24-h urine collections were analyzed for sodium, potassium, and creatinine.

Each study was begun at 8 a.m. after the subjects had been fasting and recumbent for $10 \mathrm{~h}$. An indwelling intravenous catheter was placed in each of the subject's arms-one for infusion, the other for blood sampling.

P-aminohippurate infusion. Renal plasma flow was assessed as previously described (8). In brief, a control blood sample was obtained

1. Abbreviations used in this paper: AII, angiotensin II; FET, Fisher Exact Test; PAH, $p$-aminohippurate; RBF, renal blood flow. 
METHODS
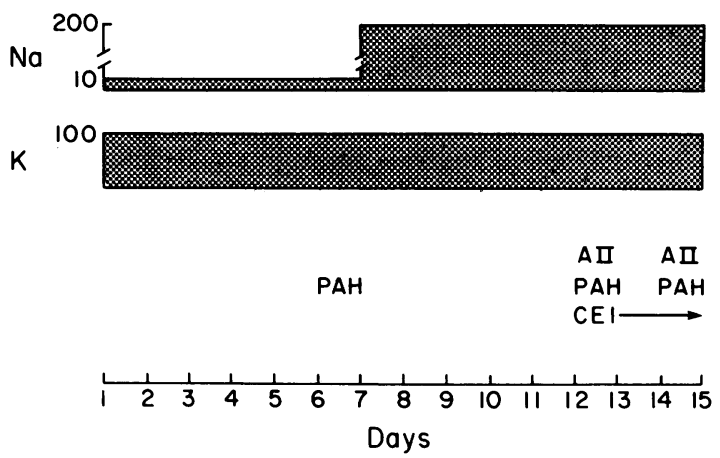

Figure 1. Schematic of protocol used. Immediately after the first infusion of AII on day 12, enalapril was administered; it was given again the following two mornings and then the AII infusion was repeated (PAH, PAH clearance; AII, angiotensin II infusion; CEI, enalapril administration).

and then an $8-\mathrm{mg} / \mathrm{kg}$ loading dose of $p$-aminohippurate (PAH) was given. A constant infusion of PAH was immediately begun at a rate of $12 \mathrm{mg} / \mathrm{min}$ using a pump (I-Med Corporation, San Diego, CA). This infusion rate achieved a plasma PAH concentration in the range in which tubular secretion dominates excretion. At this level, the clearance of PAH is not dependent on the plasma concentration, and after correction for individual body surface area, represents $\sim 90 \%$ of the effective renal blood flow. PAH clearance was calculated from the plasma concentration and the infusion rate (9). Plasma samples were obtained 45 and 60 min after the start of the constant infusion after steady state was achieved. Mean values were used in all calculations. Basal renal blood flow was assessed by this method both on the low salt and high salt diets (Fig. 1).

AII infusion. After assessment of the basal PAH clearance on the high salt diet, the patients were infused with AII amide at successive doses of 1 and $3 \mathrm{ng} / \mathrm{kg}$ per min for $45 \mathrm{~min}$ each, using an infusion pump (Harvard Apparatus Co., Inc., South Natick, MA). The constant infusion of PAH continued throughout the AII infusion to assess the change in PAH clearance with increasing AII doses. Blood pressure was monitored every 2 min with an indirect recording sphygmomanometer. Blood samples were drawn at the end of the control period and after each incremental infusion dose of AII and analyzed for PAH, AII, cortisol, sodium, and potassium.

Converting enzyme inhibition. On the afternoon after the control AII infusions were completed, the subjects were given their first dose of a converting enzyme inhibitor (enalapril). The initial dose was 5 $\mathrm{mg} ; 10 \mathrm{mg}$ was given the next morning at 8 a.m., and $20 \mathrm{mg}$ at $8 \mathrm{a} . \mathrm{m}$. on the following morning. $2 \mathrm{~h}$ later, at $10 \mathrm{a} . \mathrm{m}$. after a basal PAH clearance study, a repeat AII infusion was administered $(66 \mathrm{~h}$ after the control AII infusion) (Fig. 1).

Laboratory procedures. All blood samples were collected on ice, spun immediately, and the plasma was separated and frozen until the time of assay. Serum and urine sodium and potassium levels were measured by flame photometry using lithium as an internal standard. Serum creatinine was measured by an autoanalyzer technique. AII, plasma renal activity, aldosterone, and cortisol were assayed by radioimmunoassay techniques previously described $(10,11)$. Cross-reactivity of the AII antibody with AI was $0.2 \%$. All AII values were corrected for AII content in the sample (maximum correction was 5 $\mathrm{pg} / \mathrm{ml})$. AII levels in charcoal stripped plasma were less than the sensitivity of the assay $(7 \mathrm{pg} / \mathrm{ml})$. Plasma PAH concentration was measured by an autoanalyzer spectrophotometric technique (Technicon Instruments Corp., Tarrytown, NY) (11).

Group means have been presented with the standard error of the mean as the index of dispersion. Statistical probability was assessed with the $t$ test for paired data that were normally distributed, and the
Fisher Exact test (FET) or the Wilcoxon Signed Rank test for nonhomogeneously distributed data. Significant differences were at the $P$ $<0.05$ level unless otherwise stated. The protocol was approved by the Human Subjects Committee of the Brigham and Women's Hospital. Written informed consent for the procedures was obtained after a full description of the protocol.

\section{Results}

The hypertensive patients were subdivided into two groups according to their renovascular response to $3 \mathrm{ng} / \mathrm{kg}$ per $\mathrm{min}$ AII infusion on the high salt intake. We previously documented that normal subjects all have a decrement $>125 \mathrm{ml} / \mathrm{min}$ per $1.73 \mathrm{~m}^{2}$ with this dose $(3,8)$. Likewise, in this study, all 9 normotensive subjects and 10 of the 25 hypertensive subjects had a greater decrement. These hypertensive subjects are designated modulators. The other 15 hypertensive subjects, all of whom had a decrement $<125 \mathrm{ml} / \mathrm{min}$ per $1.73 \mathrm{~m}^{2}$, are designated nonmodulators.

Base-line comparison. The nonmodulator and modulator hypertensives included in this study were sequential admissions and did not differ significantly from each other with respect to age, sex, admission blood pressure, duration of hypertension, evidence of secondary effects of hypertension, serum creatinine, or any other identifiable physiologic characteristic (Table I). Likewise, on the three days that PAH infusion studies were performed, there were no significant differences between the normotensive subjects or the two subgroups of hypertensive patients in serum sodium, potassium, cortisol, aldosterone, AII concentration, or plasma renin activity (Table II).

Effect of sodium intake on blood pressure in hypertensives. While diastolic blood pressure was greater in the nonmodulators $(87 \pm 3 \mathrm{mmHg})$ than the modulators $(83 \pm 3 \mathrm{mmHg})$ on the sodium restricted intake, the difference did not reach statistical significance (Table II). Yet, both were considerably higher than the normotensives $(68 \pm 3 \mathrm{mmHg})$. Furthermore, the decrement in blood pressure from admission to the day the blood pressure was measured on the sodium-restricted intake was not different between the two groups. However, the arterial pressure response to salt loading in the two subgroups was different (Fig. 2). In the modulators, like the normotensives, there was no systematic change in diastolic blood pressure with salt loading, while in the nonmodulators, diastolic blood pressure rose significantly $(P<0.035)$. None of the modulators had a rise in diastolic blood pressure exceeding $3 \mathrm{mmHg}$, whereas nine of the nonmodulators had a greater rise and six of them had a rise $>10 \mathrm{mmHg}$ with salt loading (Fig. 2), a highly significant difference $(P<0.004$, FET $)$.

Table I. Clinical Characteristics of Hypertensive Patients*

\begin{tabular}{lcc}
\hline & Modulators & Nonmodulators \\
\hline Age & $44 \pm 5$ & $54 \pm 2$ \\
Percent male & $70 \%$ & $64 \%$ \\
Duration of hypertension $(y r)$ & $9 \pm 3$ & $12 \pm 3$ \\
Admission blood pressure $(m m H g)$ & & \\
$\quad$ Systolic & $147 \pm 3$ & $153 \pm 6$ \\
$\quad$ Diastolic & $92 \pm 3$ & $99 \pm 3$ \\
Serum creatinine $(m g / d l)$ & $1.0 \pm 0.1$ & $1.2 \pm 0.1$ \\
\hline
\end{tabular}

\footnotetext{
$*$ Mean \pm SEM
} 
Table II. Control Data Before Determination of PAH Clearance in Hypertensive Patients*

\begin{tabular}{|c|c|c|c|c|c|c|}
\hline \multirow[b]{2}{*}{ Sodium intake $(m e q / d)$} & \multicolumn{3}{|l|}{ Modulators } & \multicolumn{3}{|c|}{ Nonmodulators } \\
\hline & 10 & 200 & $200+$ MK421 & 10 & 200 & $200+\mathrm{MK} 421$ \\
\hline Renin activity $(\mathrm{ng} / \mathrm{ml} \mathrm{per})$ & $3.3 \pm 0.8$ & $0.5 \pm 0.1$ & $2.4 \pm 0.6$ & $3.3 \pm 0.6$ & $1.4 \pm 0.4$ & $1.5 \pm 0.5$ \\
\hline Angiotensin II $(p g / m l)$ & $38 \pm 7$ & $25 \pm 3$ & $25 \pm 3$ & $34 \pm 4$ & $23 \pm 4$ & $27 \pm 4$ \\
\hline Aldosterone $(n g / d l)$ & $25 \pm 7$ & $8 \pm 1$ & $9 \pm 1$ & $23 \pm 2$ & $9 \pm 1$ & $8 \pm 1$ \\
\hline Cortisol $(\mu g / d l)$ & $11 \pm 1$ & $9 \pm 2$ & $13 \pm 1$ & $13 \pm 1$ & $12 \pm 1$ & $12 \pm 1$ \\
\hline Sodium (meq/liter) & $135 \pm 1$ & $138 \pm 1$ & $135 \pm 1$ & $135 \pm 1$ & $138 \pm 1$ & $135 \pm 2$ \\
\hline Potassium (meq/liter) & $4.1 \pm 0.1$ & $4.1 \pm 0.1$ & $4.0 \pm 0.1$ & $4.1 \pm 0.1$ & $4.0 \pm 0.1$ & $3.9 \pm 0.1$ \\
\hline Diastolic blood pressure $(\mathrm{mmHg})$ & $82.7 \pm 2.7$ & $81.5 \pm 3.1$ & $83.7 \pm 2.7$ & $87.4 \pm 2.5$ & $93.1 \pm 4.0$ & $89.1 \pm 3.9$ \\
\hline Previous 24 -h urine sodium (meq) & $12 \pm 2$ & $207 \pm 14$ & $187 \pm 10$ & $8 \pm 1$ & $168 \pm 10$ & $186 \pm 8$ \\
\hline Potassium (meq) & $86 \pm 5$ & $86 \pm 2$ & $84 \pm 4$ & $76 \pm 5$ & $79 \pm 4$ & $85 \pm 5$ \\
\hline
\end{tabular}

* Mean \pm SEM.

$R B F$ response to sodium loading and $A I I$ administration. Basal PAH clearances among the three groups of subjects were compared on a high and low sodium intake (Fig. 3). The normotensive subjects and modulating hypertensive patients had an identical, significant increase $(79 \pm 28$ and $75 \pm 26 \mathrm{ml} /$ min per $1.73 \mathrm{~m}^{2} ; P<0.025$, paired $t$ test) in basal PAH clearance with salt loading. In contrast, nonmodulators failed to increase basal PAH clearance $\left(8 \pm 22 \mathrm{ml} / \mathrm{min}\right.$ per $\left.1.73 \mathrm{~m}^{2}\right)$.

As anticipated, because of the way the hypertensive subgroups were defined, the renovascular response to AII in the nonmodulators on the high salt diet was less than in the modulators or normotensive subjects (Fig. 4). There were no differences in the renovascular responses to AII between the modulators and the normotensive subjects. The differences in the renovascular responsiveness both to sodium loading and to exogenously administered AII in the nonmodulators could not be explained by differences in the basal systemic activity of the renin-angiotensin system (Table II); levels were indistinguishable from those of the modulators both on the low salt and the high salt diet. The RBF responses to both sodium loading and AII infusion on the high salt diet in these hypertensive patients were almost identical to what we reported

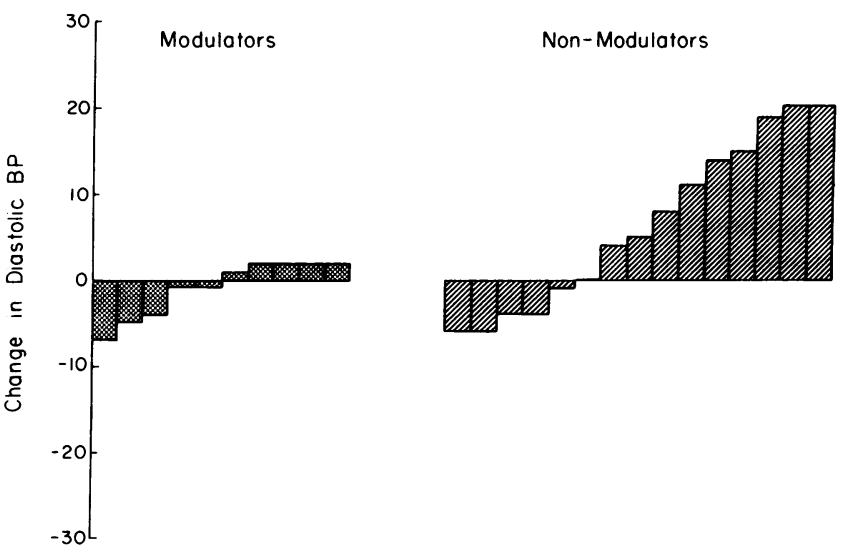

Figure 2. Frequency distribution with increment in diastolic blood pressure after $5 \mathrm{~d}$ of high sodium intake in 25 hypertensive subjects. The hypertensive subjects have been divided into modulators $(n=10)$ and nonmodulators $(n=15)$ according to their renal vascular response to AII (see text). Note that a significant pressor response ( $>10 \mathrm{mmHg}$ ) with sodium loading occurred only in the nonmodulating subgroup. The difference in the blood pressure response in the two groups was highly significant $(P<0.004)$. previously, when patients are subdivided into modulating and nonmodulating subgroups (1).

Renovascular and blood pressure responses after converting enzyme inhibition. Basal PAH clearance after $66 \mathrm{~h}$ of converting enzyme inhibition was not significantly changed in normotensives or modulators (Fig. $5 ; 11 \pm 36$ and $35 \pm 30 \mathrm{ml} / \mathrm{min}$ per $1.73 \mathrm{~m}^{2}$ ), whereas nonmodulators showed a significant increase in basal PAH clearance $\left(83 \pm 25 \mathrm{ml} / \mathrm{min}\right.$ per $1.73 \mathrm{~m}^{2}, P$ $=0.01$, paired $t$ test). Indeed, the sum of the increments in RBF with salt loading and enalapril was nearly identical in the three groups $(90 \pm 23$, normals; $110 \pm 28$, modulators; and $94 \pm 25$, nonmodulators).

Differences in RBF responsiveness to AII after converting enzyme inhibition were also observed. In the normotensive subjects and modulators, the renovascular response to AII after converting enzyme inhibition was unchanged from that observed before its administration (Fig. 4). In the nonmodulators, the renovascular response was significantly enhanced $(P=0.027, \mathrm{FET})$ after short-term converting enzyme inhibition.

There was also a difference in the effect enalapril had on arterial pressure in the two hypertensive subgroups. Converting enzyme inhibition had no appreciable effect on the diastolic blood pressure in the modulators, whereas it produced a fall in the majority of the nonmodulators (Table II and Fig. 6). As was the case with the effect of sodium loading, this can be best appreciated by examining the responses in the individual

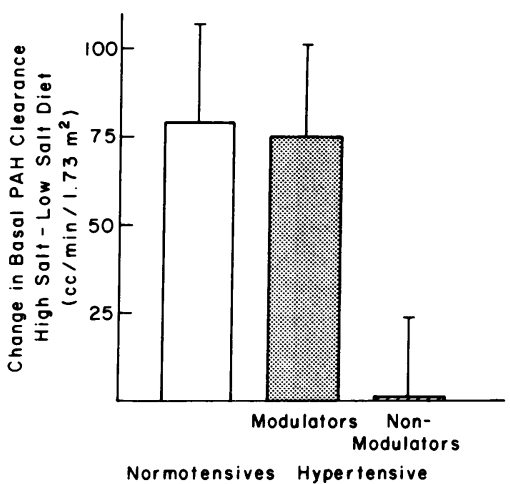

Figure 3. Increment in basal PAH clearance between low and high sodium intakes. Both normotensives $(n=9)$ and modulators $(n=10)$ significantly $(P<0.02)$ increased PAH clearance with sodium loading. In contrast, sodium loading had no effect on PAH clearance in the nonmodulators $(n=14)$. 


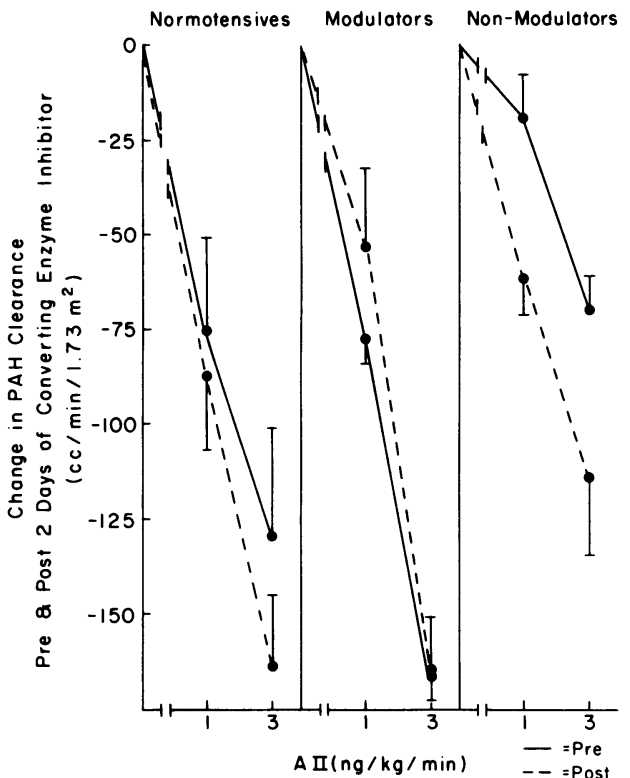

Figure 4. Decrement in PAH clearance after AII administration. Each subject was studied twice; once before and once after $66 \mathrm{~h}$ of enalapril administration. Before administration of the converting enzyme inhibitor, nonmodulators $(n=14)$ had a significantly reduced $(P<0.01)$ responsiveness to AII both when compared with modulators $(n=10)$ and to normotensive subjects $(n=9)$. After converting enzyme inhibition, the RBF response to AII did not change in the normotensives and the modulators but was enhanced significantly $(P$ $<0.027$ ) in the nonmodulating hypertensive subjects.

patients (Fig. 6). None of the modulators had a reduction in diastolic blood pressure exceeding $4 \mathrm{mmHg}$, whereas in eight of the nonmodulators the reduction was greater, a highly significant difference $(P<0.01$, FET). In most, but not all cases, the individuals who had the greatest pressor response to sodium loading also had the greatest fall in blood pressure with enalapril administration.

The pressor response to AII was not modified in either hypertensive group by converting enzyme inhibition. In response to a $3 \mathrm{ng} / \mathrm{kg}$ per min infusion of AII, the increment in diastolic pressure in the modulators pre-enalapril $(15 \pm 1 \mathrm{mmHg})$ was not different than post-enalapril $(15 \pm 1 \mathrm{mmHg})$. Similar

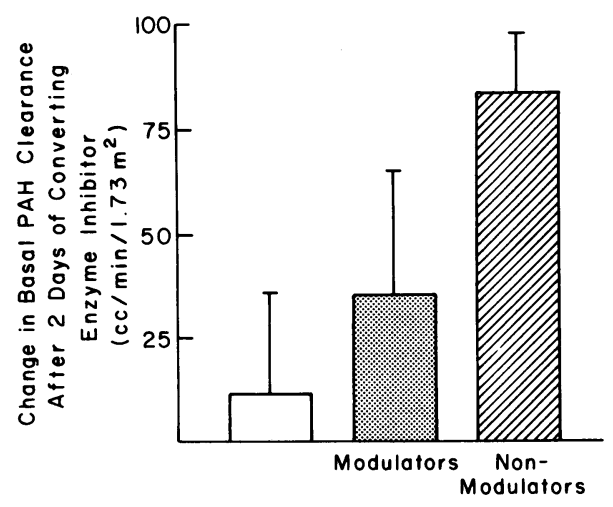

Normotensives Hypertensive

Figure 5. Change in basal PAH clearance after $48 \mathrm{~h}$ of enalapril administration. All patients were studied on a 200 meq sodium intake. Only in the nonmodulators $(n=14)$ did enalapril significantly increase basal PAH clearance $(P<0.02)$. findings were found in the nonmodulators $(16 \pm 2$ vs. $15 \pm 2$ $\mathrm{mmHg}$ ). Thus, in contrast to the renal vasculature, there was no effect of enalapril on the pressor responsiveness to AII.

\section{Discussion}

The renal blood supply makes a major contribution to maintain normal sodium homeostasis with changes in dietary sodium intake. With sodium restriction, $\mathrm{RBF}$ is reduced, facilitating sodium conservation; with sodium loading, RBF increases, promoting sodium loss $(12,13)$. Several lines of evidence suggest that the prime normal mediator of these changes is AII. First, the responsiveness of the vascular system to exogenous AII is greater on a high than a low salt intake, consistent with the fall in endogenous AII concentrations with sodium loading $(13,14)$. Second, administration of a converting enzyme inhibitor to subjects on a low salt diet increases both the basal RBF and its responsiveness to infused AII to that observed in individuals on a high salt diet $(15,16)$. Thus, two techniques (converting enzyme inhibition and high sodium intake), both of which reduce circulating, and presumably intrarenal, AII levels, normally increase basal RBF and its responsiveness to exogenously administered AII.

We have recently suggested that in a substantial fraction of patients with essential hypertension $(40 \%$ of the total population, $50 \%$ of the normal and high renin subgroup), this normal sodium-mediated modulation of renovascular response to AII is absent $(1,2)$. These individuals have the following characteristics: $(a)$ a decreased adrenal response to AII when sodium restricted $(1,3-5) ;(b)$ a decreased renal vascular response to AII when salt loaded (1); and (c) no increase in RBF after sodium loading $(1,2)$. These patients seem to comprise between 40 and $50 \%$ of the normal and high renin essential hypertensive population $(17,18)$. Because of the fixed renal vascular response to AII with shifts in sodium intake, we have termed these individuals nonmodulators. Previous studies have suggested that an increased local concentration of AII could mediate this altered renovascular response to sodium loading, but a fixed organic lesion could not be excluded. The results of this study support our original suggestion. Moreover, this study provides evidence that the abnormality may contribute to a pressor response to sodium loading.

This study reports the results in 25 hypertensive patients distinct from those reported previously $(1,2,5)$. Confirming these previous studies, nonmodulators failed to increase renal blood flow $(1,2)$ and its responsiveness to exogenously administered AII (1) with sodium loading. What factors could account for these differences in renovascular responsiveness? To answer this question, we need to examine what modifies responsiveness with changes in sodium intake in normal subjects. For the vascular smooth muscle, the mechanism underlying these changes has become increasingly clear. With increasing levels of AII in the circulation, both the renal vascular and pressor responses to AII are reduced. Similar findings have been reported when smooth muscle strips are placed in a tissue bath, supporting the hypothesis that the AII receptor is involved (12-14). Development of techniques for assessing tissue binding of radiolabeled ligands has provided additional evidence that a change in receptor function is probably the major mechanism by which vascular responsiveness to AII is modified. It is now clear that shifts in the responsiveness to AII reflect a reciprocal relationship between 


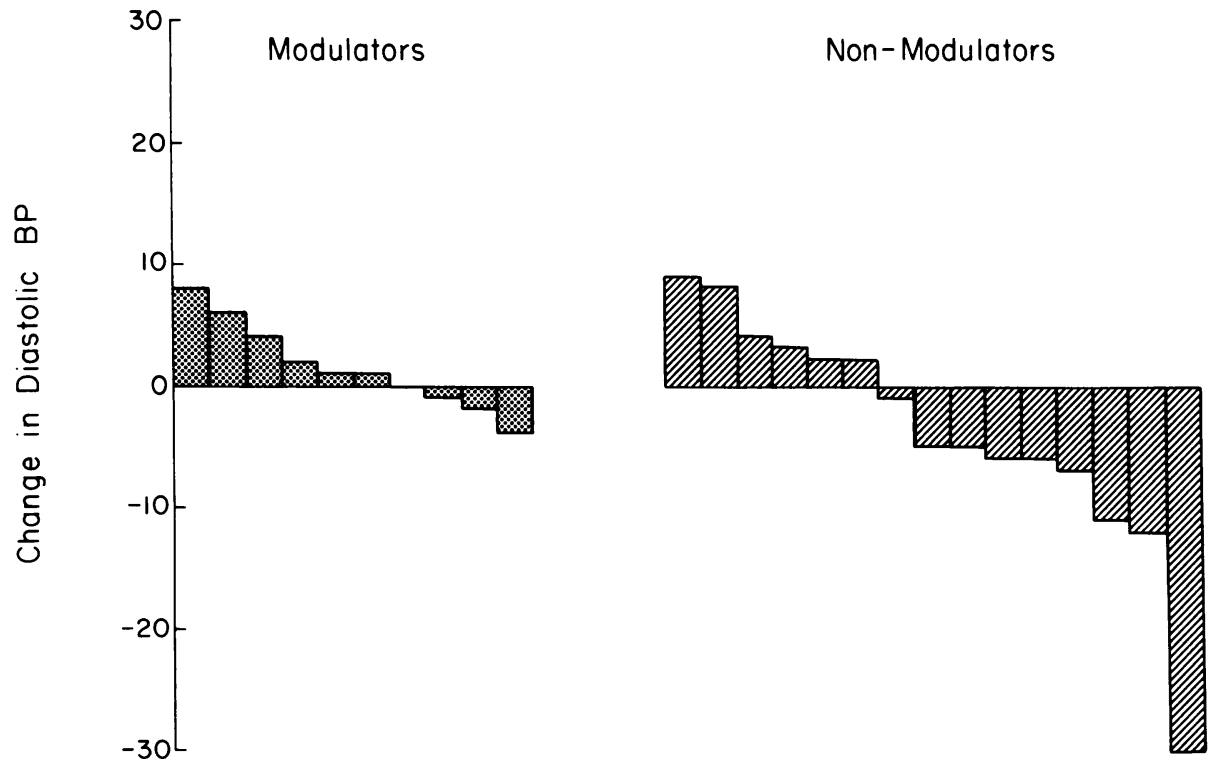

Figure 6. Frequency distribution of decrement in diastolic blood pressure after $66 \mathrm{~h}$ of enalapril administration in 25 hypertensive patients. Note that only nonmodulators $(n=15)$ had a reduction of $4 \mathrm{mmHg}$ or more in diastolic blood pressure after enalapril administration. The difference in response to enalapril between the two groups was highly significant $(P<0.01)$. local AII concentration and the number of receptors on the vascular smooth muscle (14). Thus, one possible explanation for the differences between the modulator and nonmodulator response to sodium loading could be related to nonsuppression of the renin-angiotensin system by the sodium load in the nonmodulator. Under these circumstances, one would anticipate both a smaller increment in basal RBF with the sodium load and a reduced responsiveness when exogenous AII was administered. However, no differences were found between the plasma renin activity or plasma AII concentration in the two groups (Table II). There is the possibility that sodium loading only modified the activity of the circulating and not the local, renal renin-angiotensin system. The present data, in conjunction with previous reports, make this a likely possibility.

One would anticipate, if excess renal AII, for some reason unresponsive to a sodium load, were present in nonmodulating essential hypertensives, that an anomalous increase in basal renal plasma flow would occur after converting enzyme inhibition on a high sodium intake. Indeed, this was observed.

Could the change in RBF be an effect of converting enzyme inhibition other than blocking AII formation? We, as well as others, have suggested that converting enzyme inhibitors can modify both bradykinin and prostaglandin production, either of which can cause vasodilatation (19-22). Both prostaglandins and kinins blunt, not enhance, the renal vascular response to AII. If the renal vasodilatation induced by enalapril reflected kinin or prostaglandin generation, one would not anticipate that renovascular responsiveness to infused AII would be enhanced after converting enzyme inhibition. A defect in the AII receptor cannot be excluded, although it would be difficult to explain the rapid shift in sensitivity with converting enzyme inhibition on that basis. Thus, the data are most consistent with an abnormal regulation of intrarenal AII concentration in the nonmodulators. This hypothesis would also suggest that local renin AII concentrations either are of less importance in normotensive subjects and modulators or, more likely, are more influenced in parallel with plasma concentrations by sodium intake.

Does this abnormal regulation of local AII reflect a generalized abnormality? We think not. If there was a generalized abnormality in tissue AII regulation, one would anticipate a change in pressor responsiveness to AII after converting enzyme inhibition, similar to the changes observed in the renal vasculature. Blood pressure increments with the $3 \mathrm{ng} / \mathrm{kg}$ per minute A II infusion were indistinguishable between modulators and nonmodulators both before and after enalapril, suggesting that the peripheral vascular renin-angiotensin system is involved minimally.

Other possible explanations for nonmodulation, including age, differences in the level of renal damage, differences in basal PAH clearance before administration of AII, or clinical differences expressed in the physical exam, electrocardiogram, duration of hypertension, or admission blood pressure, all are unlikely, based both on the data in this study and from previous reports $(1,23,24)$.

There has been substantial interest in sodium-sensitive normal-renin essential hypertension, but no clear indication as to its pathogenesis. A related, popular analysis of the problem has suggested a bipolar solution; volume factors on the one hand, and vasoconstriction on the other $(25,26)$. The results of this study provide insight into both. Only nonmodulators had a pressor response to sodium loading, perhaps secondary to a tendency to retain more of the sodium load (Table II). One would not anticipate that a converting enzyme inhibitor would be effective in reducing blood pressure in sodium-sensitive, apparently volume-dependent hypertension. But this study does demonstrate a rather strong correlation between sodium sensitivity of the hypertension and the depressor response after $66 \mathrm{~h}$ of converting enzyme inhibition. One clear conclusion is that the factors underlying the hypertension are substantially more complex than the present models would predict.

Finally, this study may provide an explanation for the surprising fact that $40-50 \%$ of patients on a liberal sodium intake, sufficient to suppress the renin-angiotensin system, have a substantial blood pressure reduction with converting enzyme inhibitors. The rest usually will not respond unless a diuretic is given to activate the renin-angiotensin system (2729). The responders to monotherapy may be the nonmodulators, although the precise mechanism(s) remain obscure. 


\section{Acknowledgments}

We acknowledge the expert assistance of Diane Rioux, Diane Passan, and the nursing and dietary staff of the Clinical Research Center in the performance and preparation of this study. Enalapril was kindly provided by Dr. Richard Davies of Merck Institute, West Point, PA.

These studies were supported in part by funds from the following sources: grants HL 14944, HL 16821, HL 07236, HL 29950, and AM 07315 from the National Institutes of Health; MSD Research Laboratories; and a Clinical Research Center Grant (RR 00888) from the Division of Research Resources, National Institutes of Health. Computer analysis was carried out using a CLINFO System also supported by the Clinical Research Center Grant.

\section{References}

1. Shoback, D. M., G. H. Williams, T. J. Moore, R. G. Dluhy, S. Podolsky, and N. K. Hollenberg. 1983. Defect in the sodium-modulated tissue responsiveness to angiotensin II in essential hypertension. $J$. Clin. Invest. 72:2115-2124.

2. Williams, G. H., M. L. Tuck, J. M. Sullivan, R. G. Dluhy, and N. K. Hollenberg. 1982. Parallel adrenal and renal abnormalities in young patients with essential hypertension. Am. J. Med. 72:907-914.

3. Moore, T. J., G. H. Williams, R. G. Dluhy, S. Z. Bavli, T. Himathongkam, and M. Greenfield. 1977. Altered renin-angiotensinaldosterone relationships in normal renin essential hypertension. Circ. Res. 41:167-171.

4. Dluhy, R. G., S. Z. Bavli, F. K. Leung, H. S. Solomon, T. J. Moore, N. K. Hollenberg, and G. H. Williams. 1979. Abnormal adrenal responsiveness and angiotensin II dependency in high renin essential hypertension. J. Clin. Invest. 64:1270-1276.

5. Taylor, T., T. J. Moore, N. K. Hollenberg, and G. H. Williams. 1984. Converting enzyme inhibition corrects the altered adrenal response to angiotensin II in essential hypertension. Hypertension (Dallas). 6: 92-99.

6. Shoback, D. M., G. H. Williams, N. K. Hollenberg, R. O. Davis, T. J. Moore, and R. G. Dluhy. 1983. Endogenous angiotensin II as a determinant of sodium modulated changes in tissue responsiveness to angiotensin II in normal man. J. Clin. Endocrinol. \& Metab. 57:764770.

7. Tuck, M. L., R. G. Dluhy, and G. H. Williams. 1974. A specific role for saline or the sodium ion in the regulation of renin and aldosterone secretion. J. Clin. Invest. 53:988-995.

8. Smith, H. W., W. Goldring, and H. Chasis. 1938. The measurement of the tubular excretory mass, effective blood flow, and filtration rate in the normal human kidney. J. Clin. Invest. 17:263-278.

9. Schnurr, E., W. Lahme, and H. Kuppers. 1980. Measurement of renal clearance of inulin and PAH in the steady state without urine collection. Clin. Nephrol. 13:26-29.

10. Emmanuel, R., J. P. Cain, and G. H. Williams. 1973. Double antibody radioimmunoassay of renin activity and angiotensin II in human peripheral plasma. J. Lab. Clin. Med. 81:632-640.

11. Underwood, R. H., and G. H. Williams. 1972. The simultaneous measurement of aldosterone, cortisol, and corticosterone in human peripheral plasma by displacement analysis. J. Lab. Clin. Med. 79: 848-862.

12. Sawyer, W. H., J. R. Blair-West, P. A. Simpson, and M. K. Sawyer. 1976. Renal responses of Australian lung fish to vasotoxin, angiotensin II and sodium chloride infusion. Am. J. Physiol. 231:593602.

13. Hollenberg, N. K., W. R. Chenitz, D. F. Adams, and G. H.
Williams. 1974. Reciprocal influence of salt intake on adrenal glomerulosa and renovascular responses to angiotensin II in normal man. $J$. Clin. Invest. 54:34-42.

14. Gunther, S., M. A. Gimbrone, Jr., and R. W. Alexander. 1980. Regulation by angiotensin II of receptors in resistance blood vessels. Nature (Lond.). 287:230-232.

15. Kimbrough, H. M., E. D. Vaughan, R. M. Carey, and C. R. Ayers. 1977. Effect of intrarenal angiotensin II blockade on renal function in conscious dogs. Circ. Res. 40:174-177.

16. Hollenberg, N. K., L. G. Meggs, G. H. Williams, J. Katz, J. D. Garnic, and D. P. Harrington. 1981. Sodium intake and renal responses to captopril in normal man and in essential hypertension. Kidney (NY). 20:240-245.

17. Hollenberg, N. K., and G. H. Williams. 1983. Volume control and altered renal and adrenal responsiveness to angiotensin II in essential hypertension: Implication for treatment with converting enzyme inhibition. J. Hypertension. 1(Suppl.):119-128.

18. Williams, G. H., and N. K. Hollenberg. 1984. Defect in sodiummediated adrenal responsiveness to angiotensin II in essential hypertension: implications for pathogenesis. In Is Essential Hypertension an Endocrine Disease. R. M. Carey and C. Edwards, editors. Butterworth and Co., England. In press.

19. Williams, G. H., and N. K. Hollenberg. 1977. Accentuated vascular and endocrine response to SQ20881 in hypertension. $N$. Engl. J. Med. 297:184-188.

20. Mimran, A., A. Targhetti, and B. La Roche. 1980. The antihypertensive effect of captopril-evidence for an influence of kinins. Hypertension (Dallas). 2:732-737.

21. Swartz, S. L., G. H. Williams, N. K. Hollenberg, L. Levine, R. G. Dluhy, and T. J. Moore. 1980. Captopril-induced changes in prostaglandin production. Relationship to vascular responses in normal man. J. Clin. Invest. 65:1257-1264.

22. Moore, T. J., F. R. Crantz, N. K. Hollenberg, R. J. Koletsky, M. S. LeBoff, S. L. Swartz, L. Levine, R. G. Dluhy, S. Podolsky, and G. H. Williams. 1981. Contribution of prostaglandins to the antihypertensive action of captopril in essential hypertension. Hypertension (Dallas). 3:168-173.

23. Hollenberg, N. K., M. Epstein, R. D. Guttmann, N. Conroy, R. I. Basch, and J. P. Merrill. 1970. Effect of sodium balance on intrarenal distribution of blood flow in normal man. J. Appl. Physiol. 28:312-317.

24. Hollenberg, N. K., D. F. Adams, H. S. Solomon, A. Rashid, H. L. Abrams, and J. P. Merrill. 1974. Aging and the renovasculature in normal man. Circ. Res. 34:309-316.

25. Laragh, J. H. 1973. Vasoconstriction volume analysis for understanding and treating hypertension: the use of renin and aldosterone profiles. Am. J. Med. 55:261-273.

26. Case, D. B., J. M. Wallace, H. J. Keim, M. A. Weber, J. E. Sealey, and J. H. Laragh. 1977. Possible role of renin in hypertension as suggested by renin-sodium profiling and inhibition of converting enzyme. $N$. Engl. J. Med. 296:641-648.

27. Brunner, H. R., H. Gavras, B. Waeber, G. R. Kershaw, G. A. Turini, R. A. Vukovich, D. N. McKinstry, and I. Gavras. 1979. Oral angiotensin-converting enzyme inhibitor in long-term treatment of hypertensive patients. Ann. Intern. Med. 90:19-23.

28. Johnston, C. I., J. A. Millar, B. P. McGrath, and P. B. Matthews. 1979. Long-term effects of captopril (SQ 14225) on blood pressure and hormone in essential hypertension. Lancet. II:493-496.

29. Swartz, S. L., G. H. Williams, N. K. Hollenberg, F. R. Crantz, T. J. Moore, L. Levin, A. A. Sasahara, and R. G. Dluhy. 1980. Endocrine profile in the long-term phase of converting enzyme inhibition. Clin. Pharmacol. Ther. 28:499-508. 